\title{
Erratum to: Differences among five amaranth varieties (Amaranthus spp.) regarding secondary metabolites and foliar herbivory by chewing insects in the field
}

Selene L. Niveyro • Anne G. Mortensen •

Inge S. Fomsgaard • Adriana Salvo

Published online: 1 January 2013

(C) Springer Science+Business Media Dordrecht 2012

\section{Erratum to: Arthropod-Plant Interactions}

DOI 10.1007/s11829-012-9219-y

Unfortunately, the figures were published incorrectly in the original publication of the article. The correct versions of the figures are provided below (Figs. 1, 2, 3 and 4).

The online version of the original article can be found under doi:10.1007/s11829-012-9219-y.

\section{S. L. Niveyro $(\square)$}

Facultad de Agronomía, Universidad Nacional de La Pampa, Ruta 35 Km 334, Santa Rosa 3300, La Pampa, Argentina e-mail: niveyro@agro.unlpam.edu.ar

\section{A. G. Mortensen · I. S. Fomsgaard}

Faculty of Agricultural Sciences, Department of Integrated Pest Management Research Centre, Flakkebjerg, Aarhus University, Forsøgsvej, 1, 4200 Slagelse, Denmark

\section{A. Salvo}

Centro de Investigaciones Entomológicas de Córdoba, IMBIV/ CONICET, Facultad de Ciencias Exactas Físicas y Naturales, Universidad Nacional de Córdoba, Vélez Sarsfield 1611, Córdoba, Argentina
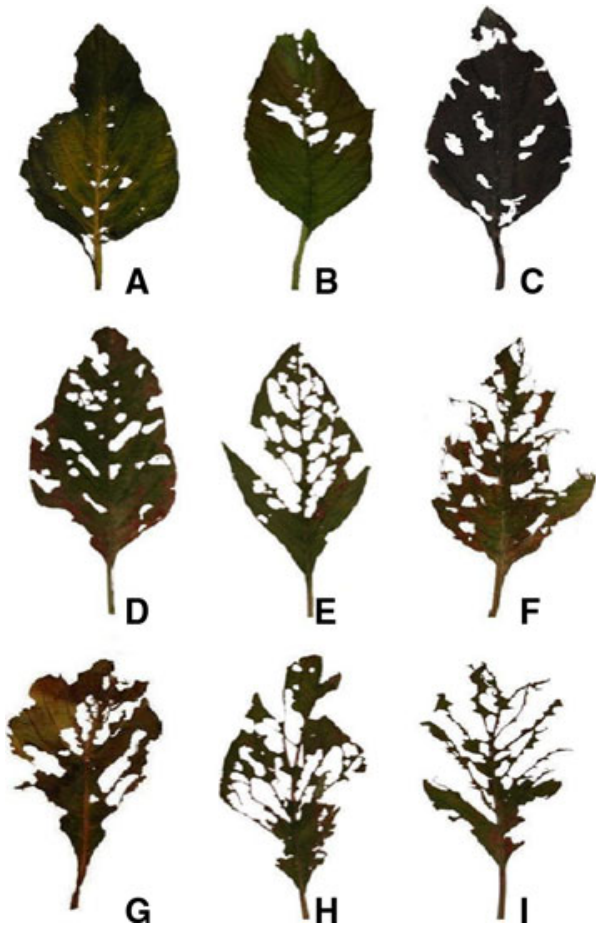

Fig. 1 Amaranthus leaves with different leaf areas removed by chewing phytophagous insects. a $1-5 \%$, b 6-10\%, c 11-20\%, d $21-30 \%$, e $31-40 \%$, f $41-50 \%$, g $51-65 \%$, h $66-75 \%$, i $76-95 \%$ 


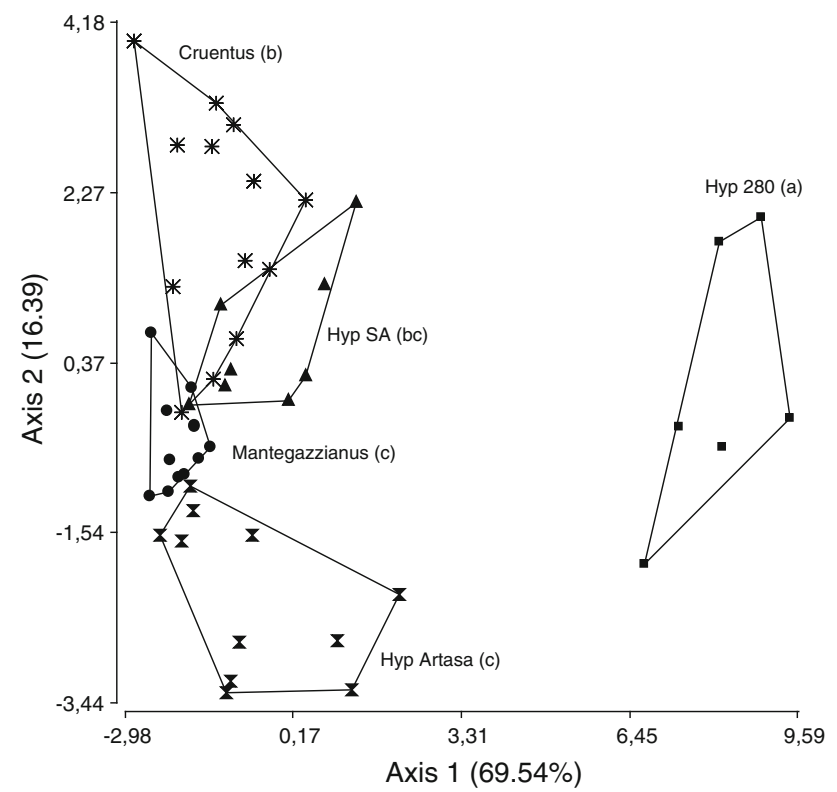

Fig. 2 Discrimination of samples of different Amaranthus varieties based on the composition of fifteen secondary metabolites. Ninetyfour percent of the samples were classified to the correct variety. Different letters following the variety names indicate significant differences according to MANOVA $(p<0.0001)$

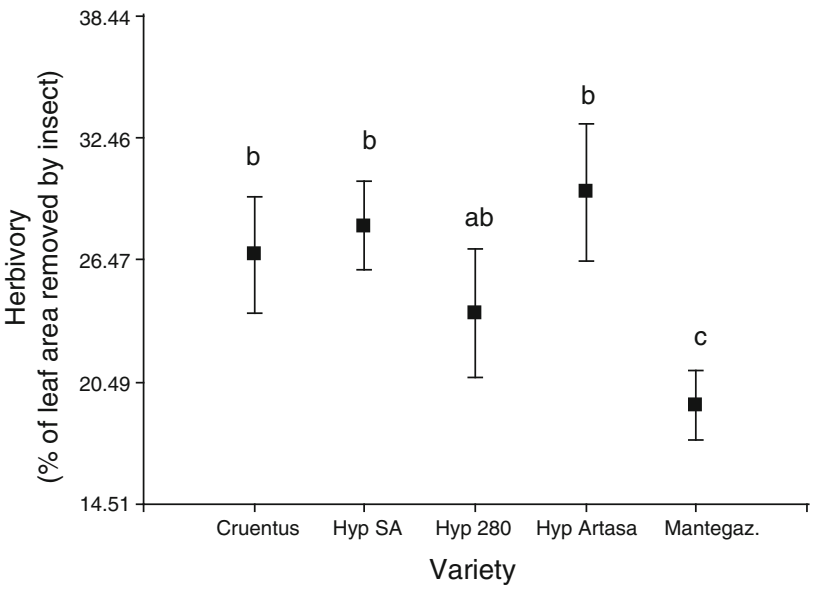

Fig. 3 Mean herbivory levels (and standard errors) recorded in plants of Amaranthus varieties. Different letters above means indicate significant differences according to the LSD test $(p=0.030)$

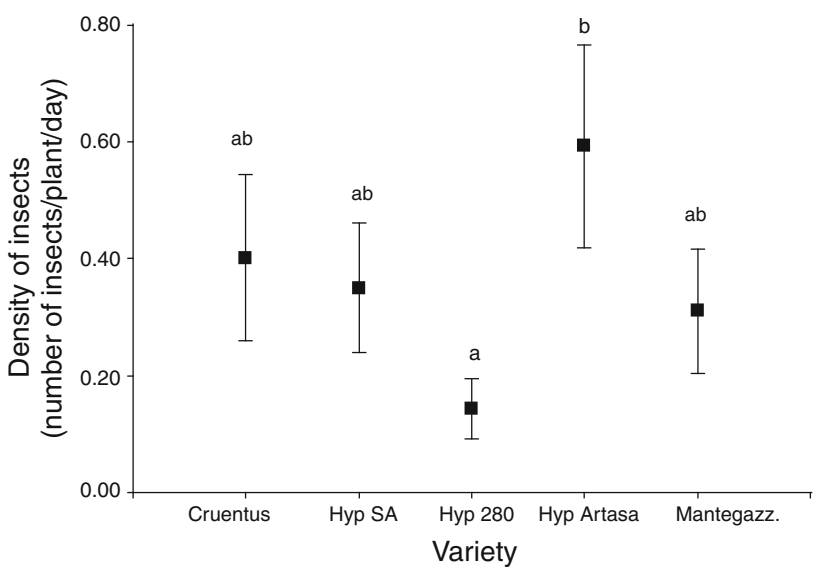

Fig. 4 Mean density of insects (and standard errors) recorded in plants of Amaranthus varieties. Different letters above means indicate significant differences according to the LSD test $(p=0.030)$ 